Research Paper

\title{
History of Dental Infections Associates with Cancer in Periodontally Healthy Subjects: A 24-Year Follow-Up Study from Sweden
}

\author{
Eunice Virtanen1, Birgitta Söder², Leif C. Andersson³, Jukka H. Meurman ${ }^{1,4}$ and Per-Östen Söder ${ }^{\bowtie}$ \\ 1. Institute of Dentistry, University of Helsinki, Helsinki, Finland. \\ 2. Department of Dental Medicine, Karolinska Institutet, Huddinge, Sweden. \\ 3. Department of Pathology, Haartman Institute, University of Helsinki, Helsinki, Finland. \\ 4. Department of Oral and Maxillofacial Diseases, Helsinki University Central Hospital, Helsinki, Finland.
}

$\square$ Corresponding author: Birgitta Söder, Karolinska Institutet, Department of Dental Medicine, Box 4064, 14104 Huddinge, Sweden. Tel: +46 852488241 Mobile: +46 8761009511 Fax: +46 86638306 E-mail: birgitta.soder@ki.se.

() Ivyspring International Publisher. This is an open-access article distributed under the terms of the Creative Commons License (http://creativecommons.org/ licenses/by-nc-nd/3.0/). Reproduction is permitted for personal, noncommercial use, provided that the article is in whole, unmodified, and properly cited.

Received: 2013.08.14; Accepted: 2013.II.01; Published: 2014.01.02

\begin{abstract}
Background: Infections of teeth are highly prevalent, often leading to tooth extractions. Missing teeth can thus be considered as proxy for chronic dental infections, caries or periodontitis. We followed-up a cohort for 24 years investigating the association between missing teeth and the incidence of cancer with the hypothesis that dental chronic inflammation links to cancer.

Methods: WHO ICD-7-9-10 malignant diagnoses were recorded from the Swedish Cancer Registry from 1985 to 2009 in I 390 individuals who had underwent clinical oral examination in 1985. The subjects appeared periodontally healthy and thus the probable reason for tooth extractions was deep caries. Using Fisher's exact t-test and multiple logistic regression analysis the results were analysed for the association between cancer incidence and baseline oral health parameters and a number of other explanatory factors.

Results: Of the I 390 subjects $7 \mid$ had got cancer by year 2009. The results of the multiple regression analysis showed that between any type of cancer as a dependent variable, and several independent explanatory variables, missing second molar in the right mandible and age appeared as the principle independent predictors significantly associating with cancer, with an odds ratio ( $95 \%$ confidence interval) of 2.62 (I.18-5.78) and I.9I (I.06-3.43), respectively.

Conclusions: In periodontally healthy subjects extracted molars, proxy for past dental infections, seemed to predict cancer risk in the studied age group - hence supporting a role of chronic dental infection/inflammation in carcinogenesis.
\end{abstract}

Key words: Dental infections, Periapical infection, Extracted molars, Cancer.

\section{Introduction}

Missing mandibular molar teeth in periodontally healthy subjects marks previously extracted teeth due to dental infection (1). Dental caries and its sequel are generally the main cause of tooth loss in people up to 50 years of age. Caries counts for $42 \%$ of extractions of teeth whereas periodontitis is the main cause of tooth loss in middle-aged and elderly people and counts for $28 \%$ of extractions $(2,3)$.
In the oral cavity the mucous membranes (4) the tongue (5) and the pharynx (6) may be reservoirs of bacterial pathogens causing focal infections and subsequent chronic inflammation (7). Many oral infections, however, seem to emanate from an undisturbed growth of oral bacteria colonizing the tooth surfaces and forming oral biofilms (dental plaque) (8). Dental diseases, caries and periodontitis, are highly prevalent 
in all populations and may also link with cancer $(9$, 10).

Hypodontia vary in retrospective radiographic studies with reported rates from $2.6 \%$ to $11.3 \%$ (11). Nationwide surveys to determine the reasons for tooth extraction have been carried out in several countries (1-3,12-14). Orthodontic reasons for extraction count for about $10 \%$ and these extractions are principally made from children (12). Thus, when considering reasons for missing teeth in populations, hypodontia and orthodontic extractions are of minor importance, especially for molar teeth.

Caries may lead to necrosis of the dental pulp with subsequent spread of infection in the apical area and beyond. The extraction of a tooth is a critical moment since there bacteria get entry into the bloodstream and consequently spread all over the body. Okell and Elliott in 1935 were the first to demonstrate the presence of bacteria in the bloodstream following dental extractions and associated bacteraemia with the risk for endocarditis. When an apical lesion progresses and the infection spreads into the alveolar bone, an abscess will be formed (15). This in turn often leads to endodontic treatment given by a dentist. However, the lesion may also become chronic when bacteria and their toxins remain at the infected site for long periods of time without causing any acute or overt clinical symptoms to the patient. Endodontic treatment may also fail and the tooth finally needs to be removed. However, in spite of treatment the associated chronic inflammation in the apical area may prevail even after the affected tooth has been extracted (16).

Studies in particular on gastrointestinal malignancies have shown that the large amount of cytokines, inflammatory mediators and growth factors released during inflammation by immune and non-immune cells may influence the process of carcinogenesis (17). Indeed, infection-driven inflammations have been estimated to be involved in the pathogenesis of approximately $15-20 \%$ of human tumours (18).

Consequently, our hypothesis of the present study was based on the paradigm of dental infection/inflammation-caused carcinogenesis. We questioned whether the low-degree chronic inflammations associated with inferred teeth, and prevailing even after removal of a tooth with apical infection, could contribute to the development of cancer. Hence the aim was to study the development of cancer in a group of periodontally healthy subjects with extracted teeth for over 20 years. By selecting periodontally healthy subjects we excluded from the analyses subjects with periodontitis thus anticipating that the reasons for tooth extractions had rather been the gener- ally highly prevalent deep caries and its complications, i.e. periapical infections.

\section{Methods}

In 1985 we undertook a study comprising a random sample of 3273 individuals aged $30-40$ years. The subjects were randomly selected from a registry file of all inhabitants $(n=105798)$ of Stockholm County born on the $20^{\text {th }}$ of any month from 1945 to 1954. The registry file including all individuals born on the $20^{\text {th }}$ of any month, from 1985 and ongoing, is a unique file from Sweden. The subjects were informed about the purpose of the study and offered clinical oral examination. In total 1676 individuals (838 men and 838 women) underwent a detailed clinical oral examination and answered a questionnaire, 51.2\% of the randomly selected patients. From those, 286 persons were diagnosed having periodontal disease $(17.1 \%)$, using the classification of 1 tooth with deep pocket $\geq 5 \mathrm{~mm}$ and bleeding on probing. The remaining 1390 subjects $(82.9 \%)$ were diagnosed periodontally healthy and represent the subjects in present study, 713 women and 677 men. Figure 1 shows the study profile.

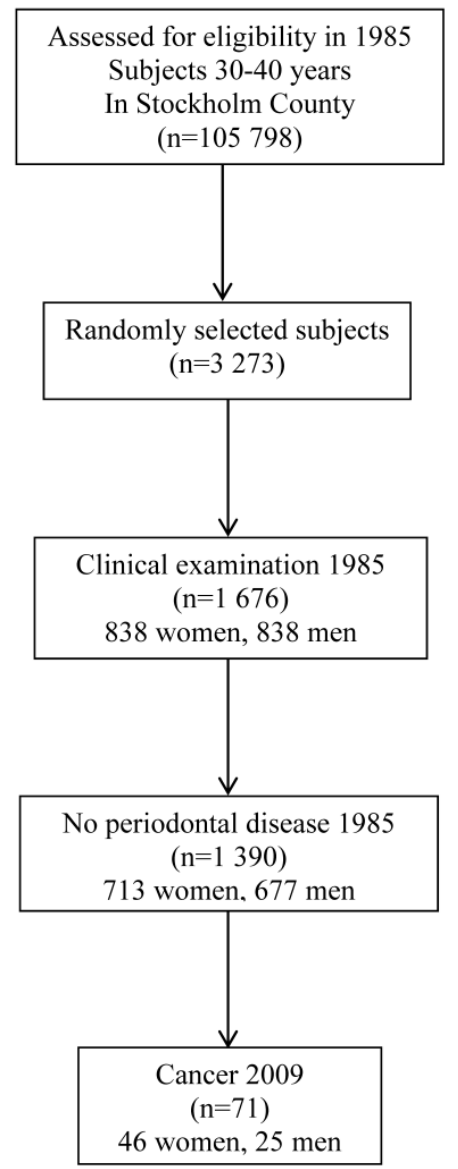

Figure I. Study profile. 


\section{Clinical recordings}

Presence or absence of teeth was recorded by counting the number of remaining teeth, excluding third molars. Gingival inflammation around every tooth was assessed using the gingival index (19) and oral hygiene status was determined using the plaque index (20) and the calculus index by assessing all six surfaces of six representative teeth according to the World Health Organization recommendations for oral health surveys. Periodontal pocket depth was measured with a periodontal probe and recorded to the nearest higher millimetre for six sites of each tooth. All teeth were examined when present, exception for the third molars. In addition, all subjects answered a questionnaire containing questions about the presence of inflammatory signs within the oral cavity and the lips, use of tobacco, reported caries and its sequel, and periodontal problems.

\section{Cancer data and socioeconomic statistics}

The data for cancer (malignant neoplasms) were obtained from the Centre of Epidemiology, Swedish National Board of Health and Welfare, Sweden. The data have been classified according to the WHO International Statistical Classification of Diseases and Related Health Problems in ICD-7, ICD-9 and ICD-10 codes. Socioeconomic data were obtained from the National Statistics Centre, Örebro, Sweden. The data for cancer incidence as well as socioeconomic status were obtained from the registry files that include data for persons born on the 20 $0^{\text {th }}$ of any month from 1985 and ongoing. This kind of register is uncommon in other countries and is indeed unique for Sweden.

\section{Ethical consideration}

The Ethics Committee of the Karolinska Institutet and Huddinge University Hospital, Sweden, approved the study protocol (Dnr 101/85 and Dnr 2007/1669-31). The study is in accordance with the Declaration of Helsinki, as revised in 1983.

\section{Statistical analyses}

Analysis of variance, chi-square tests, Fisher's exact t-test and multiple logistic regression analysis were applied when appropriate. Multiple logistic regression analysis was used to compare the incidence of cancer, according to the state of oral health at baseline, while simultaneously controlling for confounding variables. Age, gender, frequency of dental appointments, education, income, socioeconomic status, working status, pack-years of smoking, dental plaque index, calculus index, and any missing tooth were included in the model as confounders. Teeth were dummy coded according to reference cell coding with k-1 dummies. Smoking was expressed in pack-years of smoking. The model with the confounders was correlated to cancer. A backwards elimination method was used to control for multicollinearity (correlation between confounders). The statistical model was tested according to Cox \& Snell and Nagelkerke $(21,22)$. Differences between data sets with a probability of $<0.05$ were regarded as significant. All $p$-values are two-tailed, and confidence intervals were calculated at the 95\% level. All statistical analyses were performed using the PASW ${ }^{\circledR}$ Statistics software package, version 20 (PASW Inc. Chicago, IL, USA).

\section{Results}

In the total baseline cohort of 3273 randomly selected subjects $4.8 \%$ were diagnosed having cancer: 97 women and 60 men ( $p=0.001$ between genders). Cancer had been diagnosed in women at the mean age of $45.0 \pm 7.1$ years, and in men at the mean age of $43.6 \pm 9.1$ years, respectively. Of the 1390 clinically examined and diagnosed as periodontally healthy persons 71 subjects $(5.1 \%)$ were diagnosed with cancer during the follow-up: 46 women $(3.3 \%)$ and 25 men $(1.8 \%)$. The difference was significant between men and women $(p<0.05)$. Demographic clinical oral health data of this group are given in Table 1 . When comparing the subjects with and without cancer significant differences between the groups were seen in gender and age $(p<0.05$ and $p<0.001$, respectively). Furthermore the total number of missing teeth $(p<0.05)$ and the number of missing molars $(p<0.05)$ was significantly higher in 1985 among the subjects who later got cancer when compared with those who did not get cancer.

Table I. Demographic and oral clinical data of I 390 periodontally healthy subjects grouped by incidence of Cancer.

\begin{tabular}{|c|c|c|c|}
\hline & $\begin{array}{l}\text { Cancer } \\
(\mathrm{n}=71) \\
\text { number, mean } \pm \\
\text { SD }\end{array}$ & $\begin{array}{l}\text { No Cancer } \\
(n=1319) \\
\text { number, mean } \pm \\
\text { SD }\end{array}$ & $p^{*}$ \\
\hline Gender (female/male) & $46 / 25$ & $668 / 651$ & $<0.05$ \\
\hline Age in 2009 (years) & $61.1 \pm 2.5$ & $59.5 \pm 2.8$ & $<0.001$ \\
\hline $\begin{array}{l}\text { Education (compulsory } \\
\text { school/higher) }\end{array}$ & $13 / 58$ & $205 / 1114$ & NS \\
\hline Smoking (pack-year) & $2367.1 \pm 2817.4$ & $2141.3 \pm 2924.1$ & NS \\
\hline $\begin{array}{l}\text { Income (Swedish } \\
\text { Crowns } \times 1000)\end{array}$ & $180.0 \pm 94.1$ & $180.9 \pm 101.2$ & NS \\
\hline Plaque index & $0.54 \pm 0.61$ & $0.58 \pm 0.62$ & NS \\
\hline Gingival inflammation & $1.18 \pm 0.49$ & $1.18 \pm 0.47$ & NS \\
\hline Calculus index & $0.41 \pm 0.45$ & $0.46 \pm 0.59$ & NS \\
\hline Nr. missing teeth & $1.79 \pm 3.34$ & $1.16 \pm 2.31$ & $<0.05$ \\
\hline Nr. missing molars & $0.76 \pm 1.49$ & $0.47 \pm 1.15$ & $<0.05$ \\
\hline
\end{tabular}

* Fisher's exact $t$ / test or Student's t-test for unpaired samples as appropriate. Data are expressed as mean $\pm \mathrm{SD}$. 
In the multiple logistic regression model with any type of cancer as the dependent variable, missing second molar in the right mandible associated with 2.62-times the odds, and age with 1.91-times the odds with cancer, respectively, as given in Table 2. The other factors considered in the statistical model (gender, frequency of dental appointments, education, income, socioeconomic status, working status, pack-years of smoking, dental plaque index, calculus index, and other missing teeth) exerted no significant independent influence on this variable.

The different diagnoses of malignant neoplasms as expressed in the ICD-7, ICD-9 and ICD-10 classification and recorded in the present study are given in Table 3. Women with breast cancer were the dominating group, while also two men in the cohort got breast cancer. In men the types of malignancies encountered were scattered in general.

Table 2. Results of multiple logistic regression analysis of the I 390 study subjects.

\begin{tabular}{llllll}
\hline $\begin{array}{l}\text { De- } \\
\text { pendent } \\
\text { variable }\end{array}$ & $\begin{array}{l}\text { Explaining varia- } \\
\text { ble }\end{array}$ & Beta & $\begin{array}{l}\text { Chi- } \\
\text { square }\end{array}$ & $p$-value OR (95\% CI) \\
\hline & Age & 0.65 & 4.63 & 0.031 & $1.91(1.06-3.43)$ \\
Cancer & $\begin{array}{l}\text { Second molar in } \\
\text { the right side of } \\
\text { the mandible is } \\
\text { missing } \\
\text { (Tooth number 47) }\end{array}$ & 0.96 & 5.65 & 0.017 & $2.62(1.18-5.78)$ \\
& & & & \\
&
\end{tabular}

Table 3. Diagnosis in ICD-7, ICD-9 and ICD-I0 for the 7I subjects who got cancer by 2009.

\begin{tabular}{|c|c|c|}
\hline Diagnosis & $\operatorname{Men}(\mathbf{n})$ & Women (n) \\
\hline \multicolumn{3}{|l|}{ ICD-7 } \\
\hline Malignant neoplasm of connective and other soft tissues 171 & & 4 \\
\hline Malignant neoplasm of lower limb, short bones 170.8 & 2 & \\
\hline Malignant neoplasm of other endocrine gland 194 & & 1 \\
\hline Malignant neoplasm of lower jaw bone 170.1 & & 2 \\
\hline Malignant neoplasm of cervix uteri 180 & & 1 \\
\hline Malignant neoplasm of thyroid gland 193 & 2 & \\
\hline Malignant neoplasm of mediastinum, specified or secondary 197.1 & & 1 \\
\hline \multicolumn{3}{|l|}{ ICD-9 } \\
\hline Malignant neoplasm of stomach, unspecified 151.9 & 1 & \\
\hline Malignant neoplasm of main bronchus 162.2 & 1 & 1 \\
\hline Malignant neoplasm of breast, upper-inner quadrant 174.2 & & 1 \\
\hline Malignant neoplasm of upper limb, including shoulder 172.6 & 1 & \\
\hline Malignant neoplasm of other and unspecific part of face 173.3 & & 1 \\
\hline Malignant neoplasm of skin of upper limb, including shoulder 173.6 & 1 & \\
\hline Malignant neoplasm of skin, site unspecified 173.9 & & 1 \\
\hline Malignant neoplasm of parathyroid gland 194.1 & & 1 \\
\hline Lymphosarcoma 200.1 & 1 & \\
\hline Myeloid leukemia, acute 205.0 & & 1 \\
\hline Malignant neoplasm of trachea, bronchus and lung 162.1 & & 1 \\
\hline \multicolumn{3}{|l|}{ ICD-10 } \\
\hline Malignant neoplasm of pancreas C25.9 & & 2 \\
\hline Malignant neoplasm of corpus uteri C54.9 & & 1 \\
\hline Malignant neoplasm of isthmus uteri C54.0 & & 1 \\
\hline Malignant neoplasm of endometrium C54.1 & & 1 \\
\hline Malignant neoplasm of prostate NOS C61.9 & 2 & \\
\hline Malignant neoplasm of abdominal part of esophagus C15.2 & 1 & \\
\hline Malignant neoplasm of lower part of esophagus C16.5 & 1 & \\
\hline Malignant neoplasm of sigmoid colon C18.7 & & 1 \\
\hline Malignant neoplasm of rectum C20.9 & 1 & \\
\hline Malignant neoplasm of intrahepatic bile duct carcinoma C22.1 & & 1 \\
\hline Malignant neoplasm of upper lobe, bronchus or lung C34.1 & 1 & \\
\hline Malignant neoplasm of upper-outer quadrant of breast C50.4 & & 4 \\
\hline Malignant neoplasm of breast, unspecified C50.9 & 2 & 12 \\
\hline Malignant neoplasm of lower-outer quadrant of breast C50.5 & & 1 \\
\hline Malignant neoplasm of central portion of breast C50.1 & & 1 \\
\hline Malignant neoplasm of ovary C56.9 & & 1 \\
\hline
\end{tabular}


Malignant neoplasm of bladder, unspecified C67.9

Malignant melanoma of trunk C43.5

Malignant melanoma of lower limb, including hip C43.7

Malignant neoplasm of skin of other and unspecified parts of face C44.3

Malignant neoplasm of skin of lower limb, including hip C44.7

Malignant neoplasm of brain, temporal lobe C71.2

Malignant neoplasm of central meninges $\mathrm{C} 70.0$

Malignant neoplasm of brain, frontal lobe C71.1

Malignant neoplasm of cauda equine C72.1

Malignant neoplasm of connective and soft tissue of lower limb, including hip C49.2
2

1

1

1

1
2

1

1

\section{Discussion}

This study addressed the issue of history of dental infections indicated by missing or extracted mandibular molars in periodontally healthy subjects as a risk factor for cancer. The present results clearly identified missing second molar in the mandible as the principal independent predictor for cancer, thus confirming our study hypothesis, based on the paradigm that links dental chronic infection with carcinogenesis (23).

Breast cancer is the most common cancer in women in Sweden. In 2009 it represented 30\% of the cases and the average annual increase has been 1.3\% during the last two decades. In the present study the percentage of breast cancer was $42.2 \%$ of cancers among the women investigated. Compared with data from the Swedish Cancer Registry this figure is almost fifty percent higher than that in Sweden in general. In a recent study from our group we showed that death in breast cancer associated with periodontal disease (24).

Two men in our study also got breast cancer (Table 3). Carcinoma of the male breast is uncommon and counts for $0.8 \%$ of all breast cancers (25). On the other hand, prostate cancer is the most common cancer in men representing 33\% of the male cases in 2010 in Sweden. The incidence of prostate cancer is related to the use of prostate specific antigen (PSA) testing in health care and therefore it is uncertain how the incidence trend will develop over the coming years (26). However, in the present study only two cases $(7.7 \%)$ of prostate cancer was found (Table 3). This might be explained by the fairly young starting age of our cohort, namely 30-40 years. Prostate cancer is characteristically a disease of elderly men (27). Furthermore, it is of interest to observe that there were only two cases of colon cancer, one woman with malignant neoplasm of sigmoid colon, (ICD-10 C18.7) and one man with malignant neoplasm of rectum, (ICD-10 C20.9) (Table 3). In Sweden cancer of colon and rectum are among the most common sites of malignancy in both genders.

It is well established that severe dental caries is the main reason for tooth extractions in young adult populations, such as in the present study $(3,14)$. Hence, some comments should be made concerning the reliability of the results. First, the baseline subjects were randomly chosen to avoid selection bias and to ensure normal distribution of the sample variables. The large subject pool was representative of the ethnically homogenous Swedish adult population, with an age range of 10 years to limit the influence of age differences. The present study was of longitudinal prospective design, with a group of periodontally healthy subjects first examined in 1985. By excluding patients with periodontal disease we controlled the effect of this infection on the results. Furthermore, it should be emphasized that in spite of the reported frequent visits to a dentist by the subjects, they nevertheless had many missing teeth already in 1985 . The probable explanation to this observation might indeed be high caries activity with subsequently increased risk for infected teeth causing toothache and periapical infections. Secondly, the subjects were born on the $20^{\text {th }}$ in any month between 1945 and 1954 and therefore it was possible to get the diagnoses of malignant neoplasms for each participant from the Centre of Epidemiology, Swedish National Board of Health and Welfare, Sweden. Some further comments should be made about the missing molar teeth. Bacteraemia after tooth extractions or after surgical dental extractions is well documented $(28,29)$. For example, Rajasuo et al. found that surgical dental extraction clearly caused anaerobic bacteraemia of a high frequency and that it lasted longer than previously assumed (29). This and similar findings emphasize the role of oral cavity as a source of systemic infections which, as said, may even link with carcinogenesis (30, 31)

Finally, the current statistical analyses were performed with adjustment for several demographic variables and established risk factors for cancer. Including in the model were age, gender, education, socioeconomic status, oral mucosal inflammation and smoking. Therefore these known risk factors could not confound the observed association between the missing teeth and cancer. Knowing that apical perio- 
dontitis can lead to systemic inflammation (32), and based on the pathways earlier presented $(9,33)$, in Figure 2 we provide herewith simplified explanation how dental chronic infections might be associated with the development of different cancers all over the body. This depiction is in line what is known from other contexts such as chronic autoimmune inflammatory diseases and malignancies (34).

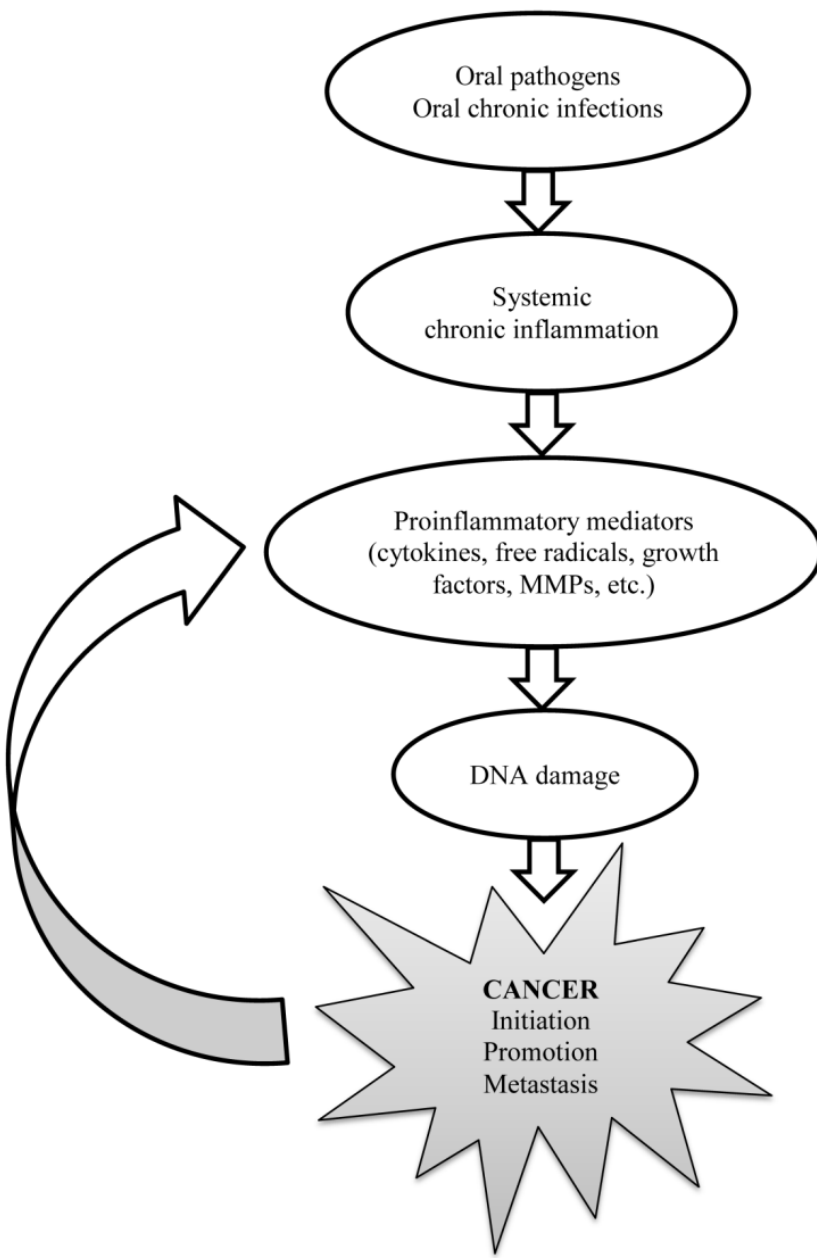

Figure 2. Explanatory pathway for the development of cancer triggered by chronic dental infections.

\section{Conclusion}

Our study hypothesis was confirmed by showing that extracted molar teeth in periodontally healthy subjects seemed to predict cancer risk in the studied age group of originally $30-40$ years individuals. The cancers were diagnosed 10 years earlier than expected, based on the national cancer register. Because teeth are mostly extracted due to dental infections, history of dental extractions and poor dental health in general, may indeed indicate higher risk to carcinogenesis.

\section{Acknowledgements}

The study was supported by the Swedish Ministry of Health and Social Affairs (grants F84/189), and Karolinska Institutet, Stockholm, Sweden; and by the Finnish Medical Society, Helsinki, and Helsinki University Central Hospital (grant TI020Y0003), Finland. The study sponsors had no involvement in the study or in the decision to submit the manuscript. A special thanks to Dr. Håkan Källmén for advice and help with statistical analysis.

\section{Competing Interests}

The authors have declared that no competing interest exists.

\section{References}

1. Trovik TA, Klock KS, Haugejorden O. Trends in reasons for tooth extractions in Norway from 1968 to 1998. Acta Odontol Scand 2000 Apr;58(2):89-96.

2. Spalj S, Plancak D, Juric H, Pavelic B, Bosnjak A. Reasons for extraction of permanent teeth in urban and rural populations of Croatia. Coll Antropol 2004 Dec; 28(2):833-839.

3. Chrysanthakopoulos NA. Reasons for extraction of permanent teeth in Greece: a five-year follow-up study. Int Dent J 2011 Feb; 61(1):19-24.

4. Fischetti VA. Novel method to control pathogenic bacteria on human mucous membranes. Ann N Y Acad Sci 2003 Apr;987:207-214.

5. Tachibana M, Yoshida A, Ansai T, Takata Y, Akifusa S, Fukuhara M, et al. Prevalence of periodontopathic bacteria on the tongue dorsum of elderly people. Gerodontology 2006 Jun; 23(2):123-126.

6. Brook I. The role of anaerobic bacteria in tonsillitis. Int J Pediatr Otorhinolaryngol 2005 Jan;69(1):9-19.

7. Gendron R, Grenier D, Maheu-Robert L. The oral cavity as a reservoir of bacterial pathogens for focal infections. Microbes Infect $2000 \mathrm{Jul}$;2(8):897-906.

8. Cullinan MP, Seymour GJ. Periodontal disease and systemic illness: will the evidence ever be enough? Periodontol 20002013 Jun;62(1):271-286.

9. Meurman JH, Bascones-Martinez A. Are oral and dental diseases linked to cancer? Oral Dis 2011 Nov;17(8):779-784.

10. Soder B, Jin LJ, Klinge B, Soder PO. Periodontitis and premature death: a 16-year longitudinal study in a Swedish urban population. J Periodontal Res 2007 Aug;42(4):361-366.

11. Larmour CJ, Mossey PA, Thind BS, Forgie AH, Stirrups DR. Hypodontia--a retrospective review of prevalence and etiology. Part I. Quintessence Int 2005 Apr;36(4):263-270.

12. Chestnutt IG, Binnie VI, Taylor MM. Reasons for tooth extraction in Scotland. J Dent 2000 May; 28(4):295-297.

13. Agerholm D. Reasons for extraction by dental practitioners in England and Wales: a comparison with 1986 and variations between regions. J Dent 2001 May; 29(4):237-241.

14. Aida J, Ando Y, Akhter R, Aoyama H, Masui M, Morita M. Reasons for permanent tooth extractions in Japan. J Epidemiol 2006 Sep; 16(5):214-219.

15. Nair PN. Pathogenesis of apical periodontitis and the causes of endodontic failures. Crit Rev Oral Biol Med 2004 Nov 1; 15(6):348-381.

16. Quirynen M, Gijbels F, Jacobs R. An infected jawbone site compromising successful osseointegration. Periodontol 2000 2003; 33:129-144.

17. Fantini MC, Pallone F. Cytokines: from gut inflammation to colorectal cancer. Curr Drug Targets 2008 May; 9(5):375-380.

18. Allavena P, Garlanda C, Borrello MG, Sica A, Mantovani A. Pathways connecting inflammation and cancer. Curr Opin Genet Dev 2008 Feb; 18(1):3-10.

19. Silness J, Loe H. Periodontal Disease in Pregnancy. Ii. Correlation between Oral Hygiene and Periodontal Condtion. Acta Odontol Scand 1964 Feb; 22:121-135.

20. Loe H, Theilade E, Jensen B. Experimental gingivitis in man. J. Periodontol. 1965; 36:177-187.

21. Cox DR, Snell EJ. On test statistics calculated from residuals. Biometrica 1971; 58:589-594.

22. Nagelkerke NJD. A note on a general definition of the coefficient of determination. Biometrica 1991; 78:691-692.

23. Chang AH, Parsonnet J. Role of bacteria in oncogenesis. Clin Microbiol Rev 2010 Oct; 23(4):837-857.

24. Soder B, Yakob M, Meurman JH, Andersson LC, Klinge B, Soder PO. Periodontal disease may associate with breast cancer. Breast Cancer Res Treat 2011 Jun; 127(2):497-502.

25. Gethins M. Breast cancer in men. J Natl Cancer Inst 2012 Mar 21; 104(6):436-438

26. Official Statistics of Sweden editor. Cancer Incidence in Sweden 2010. 2011. 
27. Hamstra DA, Bae K, Pilepich MV, Hanks GE, Grignon DJ, McGowan DG, et al. Older age predicts decreased metastasis and prostate cancer-specific death for men treated with radiation therapy: meta-analysis of radiation therapy oncology group trials. Int J Radiat Oncol Biol Phys 2011 Dec 1; 81(5):1293-1301.

28. Olsen I. Update on bacteraemia related to dental procedures. Transfus Apher Sci 2008 Oct; 39(2):173-178.

29. Rajasuo A, Perkki K, Nyfors S, Jousimies-Somer H, Meurman JH. Bacteremia following surgical dental extraction with an emphasis on anaerobic strains. J Dent Res 2004 Feb; 83(2):170-174.

30. Meurman JH. Oral microbiota and cancer. J Oral Microbiol 2010; doi:10.3402/jom.v2i0.5195.

31. Soder B, Yakob M, Meurman JH, Andersson LC, Soder PO. The association of dental plaque with cancer mortality in Sweden. A longitudinal study. BMJ Open 2012; doi:10.1136/bmjopen-2012-001083.

32. Gomes MS, Blattner TC, Sant'ana Filho M, Grecca FS, Hugo FN, Fouad AF, et al. Can Apical Periodontitis Modify Systemic Levels of Inflammatory Markers? A Systematic Review and Meta-analysis. J Endod 2013 Oct; 39(10):1205-1217.

33. Albulescu R, Codrici E, Popescu ID, Mihai S, Necula LG, Petrescu D, et al. Cytokine patterns in brain tumour progression. Mediators Inflamm 2013; 2013:979748.

34. Bende RJ, van Maldegem F, van Noesel CJ. Chronic inflammatory disease, lymphoid tissue neogenesis and extranodal marginal zone B-cell lymphomas. Haematologica 2009 Aug; 94(8):1109-1123. 